\title{
Salivary Alpha-Amylase Activity, a New Biomarker in Heart Failure?
}

\author{
Anke Suska, Urban Alehagen, Ingemar Lundström and Ulf Dahlström
}

\section{Linköping University Post Print}

N.B.: When citing this work, cite the original article.

Original Publication:

Anke Suska, Urban Alehagen, Ingemar Lundström and Ulf Dahlström, Salivary AlphaAmylase Activity, a New Biomarker in Heart Failure?, 2012, Journal of Clinical and Experimental Cardiology, (S2).

http://dx.doi.org/10.4172/2155-9880.S2-005

Postprint available at: Linköping University Electronic Press

http://urn.kb.se/resolve?urn=urn:nbn:se:liu:diva-87295 


\title{
Salivary Alpha-Amylase Activity, a New Biomarker in Heart Failure?
}

Anke Suska $^{1,2 *}$, Urban Alehagen ${ }^{3}$, Ingemar Lundstrom ${ }^{1,2}$ and Ulf Dahlstrom ${ }^{3}$

${ }^{1}$ Division of Applied Physics, Department of Physics, Chemistry and Biology (IFM), Linkoping University, Linkoping, Sweden

${ }^{2}$ Linkoping Center for Life Science Technologies (LIST), Department of Physics, Chemistry and Biology (IFM), Linkoping University, Linkoping, Sweden

${ }^{3}$ Division of Cardiovascular Medicine, Department of Medicine and Health Sciences, Faculty of Health Sciences, Linkoping University, Department of Cardiology UHL,

County Council of Ostergotland, Linkoping, Sweden

\begin{abstract}
Salivary a-amylase activity is an increasingly investigated biomarker for the activation of the autonomic nervous system. Autonomic imbalance is associated to several diseases, one of which is heart failure, and the aim of the present study was to test if salivary a-amylase activity might be a new biomarker in patients with chronic heart failure.

Methods: In this pilot study, 48 elderly men (range 59-89 years), 24 patients with established chronic heart failure in NYHA class I to III, and 24 controls were included. In all participants, saliva was collected for three consecutive days at three time points (at awakening, 30 minutes later and in the late afternoon), and blood was sampled for analysis of NT-proBNP.

Results: Within the whole group of participants, a statistically significant positive correlation between morning salivary $\alpha$-amylase activity levels and serum NT-proBNP could be found, which was strongest for the measurement taken 30 minutes after awakening, as well as a significant negative correlation of awakening $\alpha$-amylase activity levels with arterial blood pressure.

Within the control group separately, higher daily salivary a-amylase activity output correlated with increasing levels of NT-proBNP, while within the patients, the strongest association of $\alpha$-amylase activity measures were found to be a negative correlation with blood pressure.

Conclusions: Our data supports the idea that sAA activity has the potential as a non-invasive index of adrenergic activity in specific pathological conditions, though for heart failure in particular the results were merely modest, which was likely due to the specific intake of beta-receptor blocking drugs by all patients. Due to the large variability of sAA activity levels, we expect a greater potential for monitoring its changes over time, which could prove a valuable surrogate biomarker for cardiovascular diseases, including heart failure.
\end{abstract}

Keywords: Saliva; Salivary a-amylase; Alpha-amylase; Heart failure; Sympathetic nervous system; Autonomic imbalance; Biomarker

Abbreviations: BPsyst: Systolic Blood Pressure in $\mathrm{mmHg}$; BPdiast: Diastolic Blood Pressure in mmHg; NT-proBNP = N-Terminal- proB-type Natriuretic Peptide; NYHA class: New York Heart Association (NYHA) Functional Classification

\section{Introduction}

Heart failure (HF) is a serious disease with enormous clinical implications with high mortality and morbidity and poor quality of life [1].

In HF different neuroendocrine systems, including the sympathetic and the renin-angiotensin-aldosterone system are activated to maintain circulatory homeostasis and blood pressure. Norepinephrine levels and other hormones like brain natriuretic peptide (BNP), and its biologically inactive co-secreted N-terminal fragment (NT-proBNP), have been shown to be valuable prognostic markers of mortality [2-5].

In recent years, a new biomarker for assessing the activity of the sympathetic nervous system (SNS) has been proposed, the activity of salivary $\alpha$ - amylase (sAA) [6,7]. Saliva as a medium is especially attractive, as its sampling is non-invasive, and can be performed by the individual without special training [8]. Alpha-amylase is an abundant protein in human saliva. It is actively secreted by acinar cells of the salivary glands, which are innervated by nerves of both the sympathetic as well as the parasympathetic ganglion, which trigger secretion of salivary fluid and proteins via the principle neurotransmitters acetylcholine and noradrenaline, and hence the use of sAA as an exclusive read-out of sympathetic activity is strongly controversial
$[9,10]$. However it could be shown that sAA activity is increased during stress, both physical and psychological $[6,7,11]$, that it correlates with norepinephrine release [12] and that $\beta$-adrenoceptor antagonists (BBs) have a reducing effect on sAA activity levels $[13,14]$. Recent studies have also shown a tendency of higher total output of sAA in hypertensive humans, compared to normotensive ones [15].

The observed positive correlation of $\alpha$-amylase levels with the activity of the SNS, together with the advantages of saliva as a sampling medium, are compelling factors to test sAA as a biomarker for diseases, which are characterized by an autonomic imbalance, of which HF is one prominent candidate. Thus the aim of the present study is to test if sAA might be a new biomarker in patients with chronic HF.

\section{Methods}

\section{Participants}

The pilot study involved 48 men, with a median age of 77 years

*Corresponding author: Anke Suska, Division of Applied Physics, Department of Physics, Chemistry and Biology, Linkoping University, S-58183 Linkoping, Sweden, Tel: +46 13 282625; Fax: +46 13 137568; E-mail: anke.suska@liu.se

Received April 05, 2012; Accepted June 05, 2012; Published June 07, 2012

Citation: Suska A, Alehagen U, Lundstrom I, Dahlstrom U (2012) Salivary AlphaAmylase Activity, a New Biomarker in Heart Failure? J Clin Exp Cardiolog S2:005. doi:10.4172/2155-9880.S2-005

Copyright: $\odot 2012$ Suska A, et al. This is an open-access article distributed unde the terms of the Creative Commons Attribution License, which permits unrestricted use, distribution, and reproduction in any medium, provided the original author and source are credited. 
(range 59-89). The control groups, 24 men with no history of HF, were recruited through a seniors association, and $24 \mathrm{HF}$ patients were approached when coming to a check up at the Department of Cardiology, Heart Center, Linkoping University Hospital, Sweden. Only patients with advanced HF were included in the study and two participants with elevated measures of NTpro-BNP $(>720 \mathrm{pg} / \mathrm{mL})$ were excluded from the control group. No other exclusion criteria were imposed.

All 24 HF patients used BBs, in different combinations with other drugs including angiotensin converting enzyme (ACE) inhibitors, diuretics, aldosteronantagonists and angiotensin-2-receptor blockers. Five HF patients were type II diabetics and one took medication against depression.

Five participants of the controls group were hypertensive, three used BBs, and two used ACE inhibitors. Two controls were on antidepressants.

\section{Study design}

From all participants information about medication was collected, resting blood pressure and heart rate were measured, and blood samples were drawn for laboratory analysis of NTpro-BNP.

Saliva was sampled on three consecutive days on three time points (at awakening, 30 minutes after awakening, and in the evening (between 17:00 and 18:00) using salivettes (Sarstedt, Numbrecht, Germany). The participants were instructed to gently chew on the cotton pad, move it around in the mouth in circular movement for maximal 2 min. The participants recorded the day and the time of sampling on a provided paper diagram. The samples were stored in the fridge until dispatch to the university, where they were centrifuged to collect the saliva, weighted for volume determination and then kept at $-20^{\circ} \mathrm{C}$ until analysis (which was completed within a few weeks).

The study was approved by the Linkoping ethical review board, and an informed consent to participate in the trial was obtained from all the participants.

\section{Measurement of NT-proBNP}

Blood samples were analyzed for NTpro-BNP (pg/mL) at the Laboratory of Clinical Chemistry at Linkoping University Hospital using the Elecsys proBNP II assay on the Cobas e 602 immunoassay analyzer (Roche Diagnostics, Mannheim, Germany). This assay uses two monoclonal antibodies, which recognize epitopes located in the $\mathrm{N}$-terminal part (1-76) of proBNP (1-108). The total coefficient of variation was $5.2 \%$ at $149 \mathrm{pmol} / \mathrm{L}$ and $7.0 \%$ at $1409 \mathrm{pmol} / \mathrm{L}$ at this laboratory.

\section{Measurement of salivary alpha-amylase activity}

The salivary a-amylase activity (sAA) of the different saliva samples was measured using a commercially available enzyme kinetic method (Phadebas ${ }^{\circ}$ Amylase Test; Magle AB, Lund, Sweden) according to protocol (sampled were diluted from 1:500 to 1:2000); absorbance measurements were performed at $620 \mathrm{~nm}$ using a Cary 100Bio UVVisible spectrophotometer (Varian, Inc., Palo Alto, CA, USA).

The absorbance value of a blank was subtracted from that of the sample and the provided standard curve used to determine the a-amylase activity (expressed in $\mathrm{U} / \mathrm{ml}$ ). Each analysis was performed in duplicate and mean values taken (percent variation from mean was average $8 \%)$.

\section{Statistical analysis}

The data was scrutinized first by comparing the three diurnal profiles of each participant. In a few cases, when the profile gave indication of a possible mix-up of sample tubes, samples were omitted. Then, for each time point and each participant the average between the samples were taken. Additionally, the maximum percent deviation of sAA levels for each participant and each time point was calculated ((maximum absolute deviation/mean) x 100).

Kolmogorov-Smirnov statistic was used to test for normal distribution prior to statistical analyses. To compare the two groups, independent sample t-test was performed on normally distributed data and Mann-Whitney $U$ test was used when the data was not.

Area under the curve with respect to ground $\left(\mathrm{AUC}_{\mathrm{G}}\right)$ was calculated for the daily sAA output [16] and the slope of the wake-up response (Slope ${ }_{\mathrm{WR}}$; slope between sample at awakening and the one 30 min later) and the daily slope (Slope ${ }_{\mathrm{D}}$; between $30 \mathrm{~min}$ after awakening and evening (17:00 - 18:00h)) were calculated as well. Spearman's rank order correlation (rho) was performed to test for association between the variables.

Data was analyzed using IBM SPSS Statistics 19.0 (IBM, Armonk, New York, US).

\section{Results}

\section{Participants}

The characteristics of the participants are demonstrated in Table 1. The blood pressure and heart rate measures that were taken during the examination of the participants all showed statistical significant differences between the two groups. Heart rate was higher for HF patients $(t(33)=-2.6, p=0.012$, eta squared $=0.13)$, while blood pressure was lower, both systolic $(U=99, z=-3.91, p<0.0005, r=0.56)$, and diastolic ( $U=144, z=-2.99, p=0.003, r=0.43)$.

Levels of NT-proBNP in blood were significantly larger for HF patients $(U=1, z=-5.92, p<0.0005, r=0.85)$ and the patients classification according to the New York Heart Association (NYHA) Functional Classification had a median of 3 (range 1-3).

\begin{tabular}{|l|c|c|c|}
\hline Variable & Controls & Patients & Statistics \\
\hline $\boldsymbol{N}$ & 24 & 24 & \\
\hline Age & $\begin{array}{c}78.5 \\
(69-88)\end{array}$ & $\begin{array}{c}77 \\
(60-89)\end{array}$ & $p_{\mathrm{M}}=0.951$ \\
\hline Heart rate & $\begin{array}{c}64 \pm 9 \\
(45-81)\end{array}$ & $\begin{array}{c}75 \pm 19 \\
(46-120)\end{array}$ & $p_{\mathrm{t}}=0.012^{*}$ \\
\hline BPsyst & $\begin{array}{c}151.5 \\
(110-173)\end{array}$ & $\begin{array}{c}117 \\
(85-175)\end{array}$ & $p_{\mathrm{M}}<0.0005^{\star *}$ \\
\hline BPdiast & $\begin{array}{c}82 \\
(61-105)\end{array}$ & $\begin{array}{c}75 \\
(45-90)\end{array}$ & $p_{\mathrm{M}}=0.003^{\star *}$ \\
\hline NT-proBNP & $\begin{array}{c}110 \\
(46-580)\end{array}$ & $\begin{array}{c}4580 \\
(570-35000)\end{array}$ & $p_{\mathrm{M}}<0.0005^{\star *}$ \\
\hline NYHA class & 0 & $\begin{array}{c}3 \\
(1-3)\end{array}$ & $p_{\mathrm{M}}<0.0005^{\star *}$ \\
\hline
\end{tabular}

Results shown in mean \pm standard deviation (min-max) for data having normal distribution (heart rate), for all others the median (min-max) is shown.

$p$ = Sig.(2-tailed) of independent-samples t-test (normal distributed data)

$p_{u}=$ Sig.(2-tailed) of Mann-Whitney $U$ test

** Significant at the 0.01 level

* Significant at the 0.05 level

Table 1: Test for significant differences between controls and patients: Independent sample t-test for normally distributed data, Mann-Whitney $U$ test as distribution-free test. 


\section{Salivary alpha-amylase activity (sAA)}

Saliva was sampled on three time points and on three consecutive days. Figure 1 shows the mean values of the three days for all participants of the study. A line indicates the median of the data, which especially for the awakening and the evening values showed a remarkable large spread. Activity levels as low as $4 \mathrm{U} / \mathrm{ml}$ and as high as $1653 \mathrm{U} / \mathrm{ml}$ could be found in the control group alone. Additionally to the large interpersonal variation of sAA data, which is seen in the figure, a large intrapersonal deviation of the data was observed (data not shown). The maximum percent deviation within the same individual on three consecutive days for the sAA levels taken at awakening ranged from $0.5 \%-108 \%$ (median: $41 \%$ ), for the samples taken $30 \mathrm{~min}$ after awakening from $2 \%-126 \%$ (median: $34 \%$ ) and for the evening values the maximum percent deviation was 35\% - 95\% (median: $29 \%$ ).

Table 2 shows that there was no statistically significant difference between the sAA levels of the two groups at awakening ( $U=357$, $z=1.42, p=0.155, r=0.2), 30$ min afterwards $(U=372, z=1.73, p=0.083$, $r=0.25)$ or in the evening ( $U=306, z=0.37, p=0.711, r=0.05)$. Although not statistically significant, it should be pointed out that the effect size between the two groups was highest for the measurements taken 30 min after awakening, with patients having higher values than controls.

The analyzed samples were used to compute area under the curve with respect to ground $\left(\mathrm{AUC}_{\mathrm{G}}\right)$ as well as the slope of the wake-up response (Slope ${ }_{\mathrm{WR}}$; slope between first and second measurement of the day) and the daily trajectory (Slope $e_{D}$; slope between second and third measurement of the day). These three computed additional measures did not show a statistically significant difference between the two groups (Slope $\mathrm{wR}_{\mathrm{WR}}: U=273, z=-0.31, p=0.757, r=0.04$ and Slope $\mathrm{D}_{\mathrm{D}}: U=275$, $z=-0.27, p=0.789, r=0.04)$, however the $\mathrm{AUC}_{\mathrm{G}}$ measure showed a small effect size with patients having higher levels than controls $(t(40)=-1.4$, $p=0.179$, eta squared $=0.04$ ).

Additionally to the data shown in the table, the volumes of the received saliva samples (which had been categorized) were compared between the two groups. There was a significant difference in the volume of the salivary samples taken in the morning delivered by the two different groups (at awakening: $U=114, z=-3.79, p<0.0005, r=0.55$; 30min after awakening: $U=115, z=-3.72, p<0.0005, r=0.54)$, but not for samples taken in the evening $(U=209, z=-1.75, p=0.081, r=0.25)$.

\section{Correlation analysis of complete data}

Spearman's rank correlation coefficients were computed to check for associations between the different variables. The different sAA measures (individual as well as computed) were highly associated with each other, except for the slope of the wake-up response, which shows no significant correlation with the $30 \mathrm{~min}$ after awakening measurement (data not shown). The time of awakening, and the volumes of the samples were not associated with none of the $a$-amylase measures, and neither did the presence of type II diabetes or depression (data not shown)

Table 3 shows the spearman's rho and the respective $p$-values for the associations between the different sAA measures and different variables. The age of the participants correlated positively with awakening levels of sAA, and systolic, as well as diastolic blood pressure correlated negatively with higher levels of morning sAA levels, reaching statistical significance for the measurements at awakening. Most importantly however, both morning measures correlated positively with blood NT-proBNP levels, reaching statistical significance. Figure 2 shows the scatter-graph between NT-proBNP and the sAA levels 30 minutes

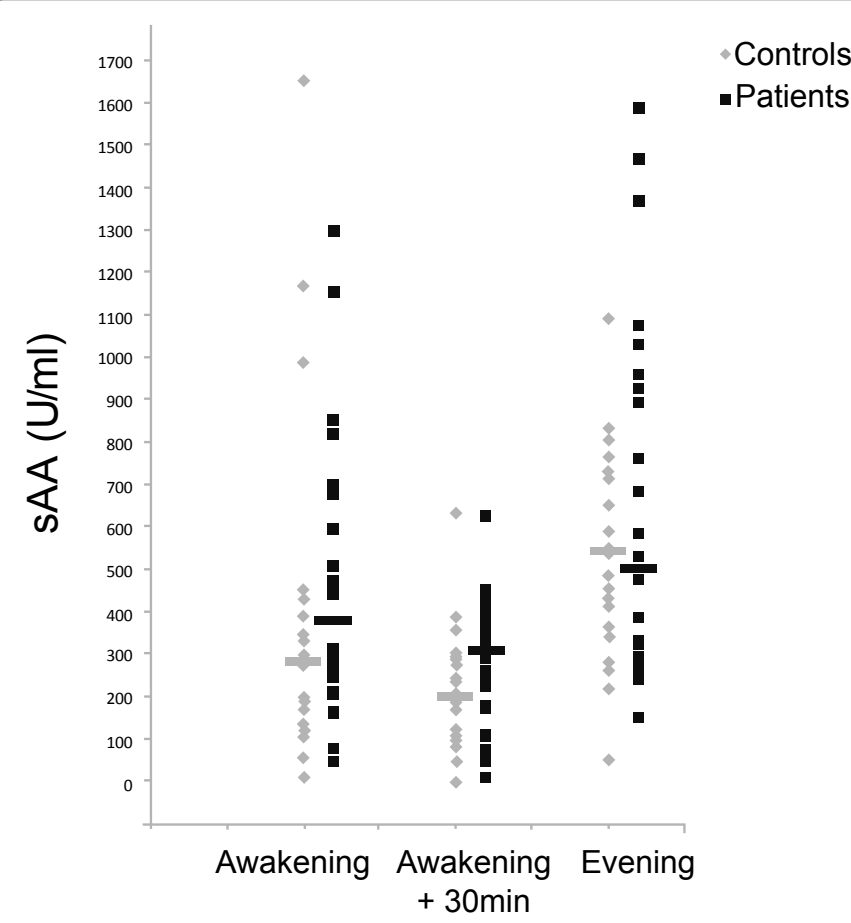

Figure 1: Mean salivary alpha-amylase activity (sAA) levels $(\mathrm{U} / \mathrm{ml})$ from three consecutive days sampled at three different time points, i.e. at awakening, 30 later and evening (between 17:00 and 18:00). Controls are in grey $(N=24)$ and heart failure patients in black $(N=24)$. The lines indicate the median of the samples.

\begin{tabular}{|c|c|c|c|}
\hline Variable & Controls & Patients & Statistics \\
\hline sAA at awakening $(\mathrm{U} / \mathrm{ml})$ & $\begin{array}{l}284 \\
(10-1653)\end{array}$ & $\begin{array}{l}379 \\
(49-1300)\end{array}$ & $p_{\mathrm{M}}=0.155$ \\
\hline sAA at awakening $+30 \mathrm{~min}(\mathrm{U} / \mathrm{ml})$ & $\begin{array}{l}199 \\
(4-633)\end{array}$ & $\begin{array}{l}307 \\
(10-625)\end{array}$ & $p_{\mathrm{M}}=0.083$ \\
\hline sAA at evening (U/ml) & $\begin{array}{l}545 \\
(51-1095)\end{array}$ & $\begin{array}{l}503 \\
(153-1590)\end{array}$ & $p_{\mathrm{M}}=0.711$ \\
\hline $\mathrm{AUC}_{\mathrm{G}}(\mathrm{U} / \mathrm{ml})$ & $\begin{array}{l}3858 \pm 1888 \\
(281-9211)\end{array}$ & $\begin{array}{l}4803 \pm 2806 \\
(830-10336)\end{array}$ & $p_{\mathrm{t}}=0.179$ \\
\hline Slope $_{\mathrm{WR}}$ & $\begin{array}{l}-102 \\
(-2039-96)\end{array}$ & $\begin{array}{l}-235 \\
(-1925-303)\end{array}$ & $p_{\mathrm{M}}=0.757$ \\
\hline Slope $_{D}$ & $\begin{array}{l}31 \\
(4-57)\end{array}$ & $\begin{array}{l}25 \\
(-9-130)\end{array}$ & $p_{\mathrm{M}}=0.789$ \\
\hline
\end{tabular}

Results shown in mean \pm standard deviation (min-max) for data having normal distribution $\left(\mathrm{AUC}_{\mathrm{G}}\right.$ ), for all others the median (min-max) is shown. $p_{\mathrm{t}}=$ Sig.(2-tailed) of independent-samples t-test $p_{M}=$ Sig.(2-tailed) of Mann-Whitney $U$ test

Table 2: Test for significant differences in SAA variables between controls and patients: Independent sample t-test for normally distributed data, Mann-Whitney $U$ test as distribution-free test.

after awakening (after ranking the data) demonstrating the significant and positive, however relatively small correlation (rho $=0.353, N=48$, $p=0.014)$.

\section{Correlation analysis within controls and patients separately}

When exploring the relationships among the variables within the control and the patient group separately, slightly different associations emerged (Table 4). Only within the control group NT-proBNP levels remained statistical significantly correlated with a sAA measure, the daily output of sAA $\left(\mathrm{AUC}_{\mathrm{G}}\right)$. Heart rate and systolic blood pressure 


\begin{tabular}{|l|l|l|l|l|l|l|}
\hline & $\begin{array}{l}\text { SAA } \\
\text { awakening }\end{array}$ & $\begin{array}{l}\text { SAA awake } \\
+30 \mathrm{~min}\end{array}$ & sAA evening & AUC $_{\mathbf{G}}$ & Slope $_{\text {wR }}$ & Slope $_{\mathbf{D}}$ \\
\hline Age & $0.292^{*}$ & 0.153 & 0.207 & 0.212 & -0.201 & 0.172 \\
& $p=0.044$ & $p=0.298$ & $p=0.159$ & $p=0.148$ & $p=0.170$ & $p=0.242$ \\
\hline Heart & 0.265 & 0.179 & 0.272 & 0.262 & -0.233 & 0.267 \\
rate & $p=0.069$ & $p=0.223$ & $p=0.061$ & $p=0.072$ & $p=0.111$ & $p=0.067$ \\
\hline \multirow{2}{*}{ BPsyst } & $-0.327^{*}$ & -0.263 & -0.239 & -0.278 & 0.226 & -0.247 \\
& $p=0.023$ & $p=0.071$ & $p=0.102$ & $p=0.056$ & $p=0.123$ & $p=0.090$ \\
\hline \multirow{2}{*}{ BPdiast } & $-0.338^{*}$ & -0.282 & -0.228 & -0.273 & 0.220 & -0.199 \\
\cline { 2 - 7 } & $p=0.019$ & $p=0.052$ & $p=0.119$ & $p=0.060$ & $p=0.133$ & $p=0.174$ \\
\hline NT- & $0.296^{*}$ & $0.353^{*}$ & 0.160 & 0.243 & -0.131 & 0.059 \\
proBNPP & $p=0.041$ & $p=0.014$ & $p=0.277$ & $p=0.097$ & $p=0.374$ & $p=0.688$ \\
\hline
\end{tabular}

* Significant at the 0.05 level (2-tailed)

Table 3: Spearman correlation coefficients (rho) and significance level ( $p$, 2-tailed) between different sAA measures $(N=48)$ and various variables.

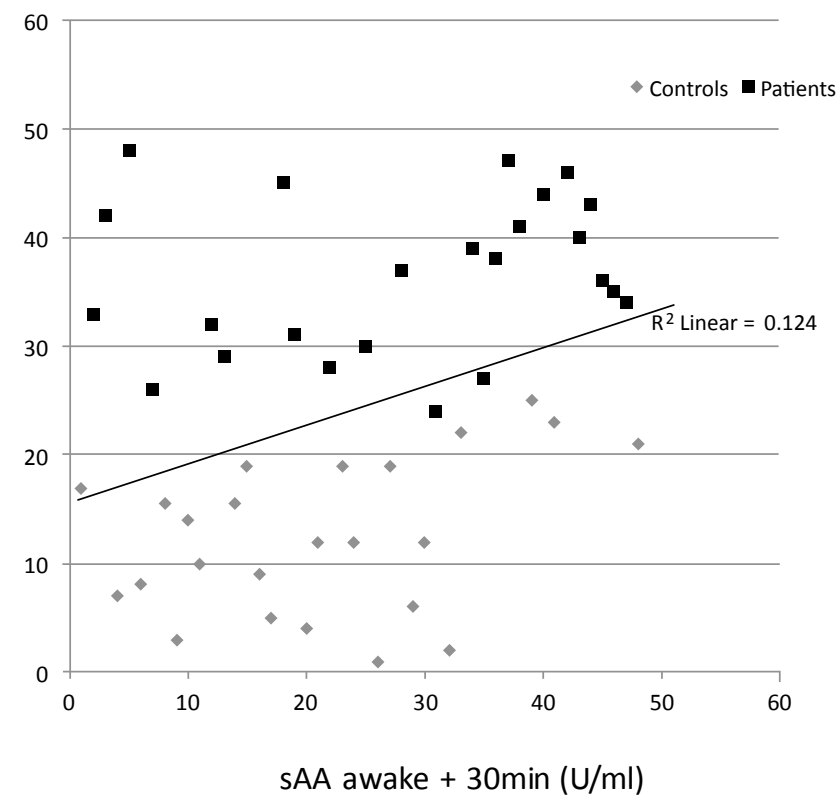

Figure 2: Scatterplot of NT-proBNP versus salivary alpha-amylase activity (sAA) at 30 minutes after awakening with regression line (ranked data). Patients (black squares, $N=24$ ) and controls (gray diamond, $N=24$ ) are shown.

showed significant associations to the sAA daily trajectory ( slope $_{\mathrm{D}}$ ). Two more sAA measures showed a medium strong relationship to NTproBNP with correlation coefficient rho above 0.3 (awake+ 30min and evening), however this association did not reach statistical significance.

Among the patients statistically significant associations were only found between heart rate and the slope of the wake-up response $\left(\right.$ Slope $\left._{\mathrm{WR}}\right)$ and between the awakening sAA levels and the diastolic blood pressure measurements. Two medium strong relationships above rho 0.3 were seen between sAA measures (sAA evening and AUCg) and the NYHA class, however not reaching statistical significance.

\section{Discussion}

This work was triggered by the question if sAA activity, a promising non-invasive biomarker of the SNS [6-15] has the potential of being a biomarker in HF. HF and other cardiovascular diseases are often associated with SNS overactivity and norepinephrine, another biomarker of sympathetic overactivity, has shown to be an important predictor of all-cause mortality and first morbid events in HF [16]. Saliva sampling and sAA activity measurements are simpler compared to analysis of neurohormones, which are relatively unstable in plasma, and hence sAA measurements on a routine basis could be easier implemented.

It is known that salivary a-amylase activity (sAA) levels show a pronounced diurnal profile with high levels at awakening, decreased levels 30 minutes afterwards and a more or less constant rise towards the late afternoon. Hence, only the comparison of sAA level measurements taken at the same time of the day is a sensible procedure. Additionally to absolute values at different time points, computed measures of the daily profile could also contain potentially useful information [17]. For the pilot study presented here, 48 participants were recruited, all men in the age between 59 and 89 . We chose to restrict our study to one age group having the same sex, as both factors have previously shown to influence sAA diurnal profiles $[18,19]$. The participants of this study were of an age considerably higher than most studies investigating sAA as a biomarker of adrenergic activity and HF patients in particular were, to the best of our knowledge, never studied in this setting.

Correlation analysis of our own data confirms the effect of age, showing a positive correlation between sAA values at awakening and participants age. As a higher activity of the SNS is generally observed with increasing age, this result is in line with the notion of using sAA levels as its marker $[6,19,20]$, and highlighting the awakening sAA values as the best candidate.

The sAA levels showed large interpersonal (as shown in Figure 1) as well as intrapersonal variations [6]. Possible dietary influences on sAA levels, as considered by B.T Squires in the $1950^{\text {th }}$ [21], could not be ruled out, however, the participants were all elderly Swedish men, and dietary differences were not expected to be high. Salivary $a$-amylase expression is discussed as a biomarker for a variety of other health conditions, including Sjogren syndrome, type I diabetes, graft-versushost disease, dental caries and periodontitis [22, 23]. The participants of this study were asked to list all regularly taken medication and present diseases and none of the above mentioned conditions were among them. It can however not be ruled out that especially the dental diseases were not mentioned although present, which could have contributed to high sAA variability. On the other hand do studies, which indicate a positive correlation between oral health conditions and elevated sAA protein levels not give a causal relationship between the two. In the case of dental caries for example, elevated sAA levels are proposed to promote the formation of caries by supporting bacteria's carbohydrate metabolisms [24] and not the other way around, i.e. that prevalence of dental caries effects sAA expression or excretion. If the causal relationships are in this way, prevalence of oral health conditions do not have relevance for the present investigation, however their direct consideration in future investigations would be of interest.

A more profound influence for interpersonal differences however can be expected to arise from genetic variations. Individual copy number variation of the salivary amylase gene, encoded by AMY1 (from 2 to up to 15 diploid copies being possible), as well as the presence of different salivary amylase protein variants have been reported $[25,26]$, and it could be shown that AMY1 copy number correlates positively to salivary amylase concentration and enzymatic activity levels [27]. An additional source of variability could arise from differences in post translational modifications of the protein, including glycosylation, deamidation and truncations [28].

The high intra-personal variation between different days, might have had psychophysiological reasons. Increasing levels of stress, either physiological or psychological in nature, have been shown to 


\begin{tabular}{|c|c|c|c|c|c|c|c|}
\hline & & sAA awakening & sAA awake $+30 \mathrm{~min}$ & sAA evening & $\mathrm{AUC}_{\mathrm{G}}$ & Slope $_{\mathrm{WR}}$ & Slope $_{\mathrm{D}}$ \\
\hline \multirow[t]{4}{*}{$\begin{array}{l}\text { Controls } \\
n=24\end{array}$} & Heart rate & $\begin{array}{c}0.109 \\
p=0.613\end{array}$ & $\begin{array}{c}0.059 \\
p=0.785\end{array}$ & $\begin{array}{c}0.353 \\
p=0.091\end{array}$ & $\begin{array}{c}0.277 \\
p=0.190\end{array}$ & $\begin{array}{c}0.037 \\
p=0.862\end{array}$ & $\begin{array}{c}0.431^{*} \\
p=0.035\end{array}$ \\
\hline & BTsyst & $\begin{array}{c}-0.183 \\
p=0.391\end{array}$ & $\begin{array}{c}-0.178 \\
p=0.406\end{array}$ & $\begin{array}{c}-0.384 \\
p=0.096\end{array}$ & $\begin{array}{c}-0.348 \\
p=0.096\end{array}$ & $\begin{array}{c}0.060 \\
p=0.780\end{array}$ & $\begin{array}{c}-0.456^{*} \\
p=0.025\end{array}$ \\
\hline & BTdiast & $\begin{array}{c}-0.111 \\
p=0.606\end{array}$ & $\begin{array}{c}-0.061 \\
p=0.777\end{array}$ & $\begin{array}{c}-0.193 \\
p=0.367\end{array}$ & $\begin{array}{c}-0.252 \\
p=0.235\end{array}$ & $\begin{array}{c}0.192 \\
p=0.369\end{array}$ & $\begin{array}{c}-0.232 \\
p=0.274\end{array}$ \\
\hline & NT-proBNP & $\begin{array}{c}0.253 \\
p=0.233\end{array}$ & $\begin{array}{c}0.317 \\
p=0.131\end{array}$ & $\begin{array}{c}0.303 \\
p=0.150\end{array}$ & $\begin{array}{c}0.423^{*} \\
p=0.039\end{array}$ & $\begin{array}{c}-0.182 \\
p=0.394\end{array}$ & $\begin{array}{c}0.186 \\
p=0.384\end{array}$ \\
\hline \multirow[t]{5}{*}{$\begin{array}{l}\text { Patients } \\
n=24\end{array}$} & Heart rate & $\begin{array}{c}0.317 \\
p=0.131\end{array}$ & $\begin{array}{c}0.094 \\
p=0.662\end{array}$ & $\begin{array}{c}0.222 \\
p=0.298\end{array}$ & $\begin{array}{c}0.181 \\
p=0.397\end{array}$ & $\begin{array}{l}-0.409^{*} \\
p=0.047\end{array}$ & $\begin{array}{c}0.284 \\
p=0.179\end{array}$ \\
\hline & BTsyst & $\begin{array}{c}-0.353 \\
p=0.091\end{array}$ & $\begin{array}{c}-0.217 \\
p=0.309\end{array}$ & $\begin{array}{c}-0.151 \\
p=0.482\end{array}$ & $\begin{array}{c}-0.193 \\
p=0.366\end{array}$ & $\begin{array}{c}0.324 \\
p=0.123\end{array}$ & $\begin{array}{c}-0.217 \\
p=0.309\end{array}$ \\
\hline & BTdiast & $\begin{array}{l}-0.467^{\star} \\
p=0.021\end{array}$ & $\begin{array}{c}-0.342 \\
p=0.102\end{array}$ & $\begin{array}{c}-0.301 \\
p=0.153\end{array}$ & $\begin{array}{c}-0.338 \\
p=0.106\end{array}$ & $\begin{array}{c}0.296 \\
p=0.160\end{array}$ & $\begin{array}{c}-0.251 \\
p=0.236\end{array}$ \\
\hline & NT-proBNP & $\begin{array}{c}0.249 \\
p=0.241\end{array}$ & $\begin{array}{c}0.223 \\
p=0.294\end{array}$ & $\begin{array}{c}0.138 \\
p=0.519\end{array}$ & $\begin{array}{c}0.173 \\
p=0.419\end{array}$ & $\begin{array}{c}-0.195 \\
p=0.362\end{array}$ & $\begin{array}{c}0.134 \\
p=0.533\end{array}$ \\
\hline & NYHA class & $\begin{array}{c}0.279 \\
p=0.186\end{array}$ & $\begin{array}{c}0.213 \\
p=0.327\end{array}$ & $\begin{array}{c}0.326 \\
p=0.120\end{array}$ & $\begin{array}{c}0.308 \\
p=0.142\end{array}$ & $\begin{array}{c}-0.123 \\
p=0.568\end{array}$ & $\begin{array}{c}0.303 \\
p=0.150\end{array}$ \\
\hline
\end{tabular}

* Significant at the 0.05 level

Table 4: Spearman correlation coefficients (rho) and significance level $(p, 2$ tailed $)$ for the control group $(N=24)$ and the patient group $(N=24)$ separately.

affect sAA levels in humans [6]. Data on stress measures have not been assessed during this study, however it is not likely that acute stress levels would vary considerably between three days in this particular group of participants, with all men being retired and the sampling of saliva, in comparison with the sampling of blood, is supposed to be less stressful to the participants. One more likely reason for the high intrapersonal variation might be due to saliva sampling artifacts using the salivette system. The system consists of an absorbent material, i.e. a cotton pad, which the participants were instructed to move around in the mouth in circular movement. Although comfortable and easy to do, it is not guaranteed that the participants sampled saliva in a comparable way, and it could be shown that saliva sampled from different salivary glands differ in sAA levels, with parotid gland having the highest level $[8,29]$. On the other hand, and most likely, were sampling artifacts only added to an inherent intrapersonal variation, which could be found also with other salivary analytes [30], as well as with other saliva sampling techniques (own unpublished data) and should be a matter of further investigation in order to increase the usefulness of this biomarker and salivary diagnostics in general.

Our study did not find a statistical significant difference between the control and the HF group in any of the sAA measures taken, which is understandable considering the strong interpersonal variation between sAA levels and the small number of participants in this pilot-study. However, there is a strong tendency of morning values being higher in patients, with the measurement taken $30 \mathrm{~min}$ after awakening showing the clearest distinction. BBs, which are taken by all patients are known to decrease sAA levels $[14,15]$. Unfortunately, the time of intake of medication was not recorded, however most likely did this happen after the second morning-measurement, $30 \mathrm{~min}$ after awakening, and the fact that stronger differences between control and patients were seen in the morning was possibly due to decreased drug levels in blood in the morning just before medication intake. If this was the case, sAA might have a value to non-invasively study therapeutic treatment compliancy and/or effects.

What might have additionally contributed to the modesty of this result could be the fact that volumes of saliva morning samples of patients were significantly lower in patients than in controls, due to the intake of diuretics. It had been shown that percent recovery of sAA from salivette cotton pads at low sample volumes $(\leq 500 \mu \mathrm{l})$ could be as low as between 0 and 70 percent [31]. In our study, 8 out of 24 patients delivered such low saliva volumes (compared with only one control), which might have artificially decreased sAA levels.

Spearman's rank correlation analysis using all the data did show a significant positive correlation between both morning sAA levels and NT-proBNP, with the measurement $30 \mathrm{~min}$ after awakening having the highest effect size. NT-proBNP, co-secreted with the biological active B-type natriuretic peptide (BNP), is produced and secreted by ventricular cardiomyocytes and the main physiologic action of BNP in $\mathrm{HF}$ is believed to be natriuresis and the promotion of vasodilatation $[32,33]$. However, also an inhibitory effect on the SNS is known [34]. The observed positive correlation of NT-proBNP with a marker of sympathetic activity seems counterintuitive, however due to the complex interplay between vasoconstrictor and vasodilator hormones and the body's adaptation mechanisms to overstimulation (like downregulation of receptors) the parallel up regulation of both systems might add significant prognostic value in patients with $\mathrm{HF}$, which our study however only can suggest.

In our study, lower blood pressure values correlated significantly with higher sAA awakening levels, opposing results found by J. Strahler et al. [15] who found a trend towards higher diurnal output of sAA in hypertensive individuals and in individuals taking antihypertensive drugs this difference was smaller. Decisive differences between the two studies could have been first the age of the participants, ours being considerably older, second the prevalence of HF in our own study group and the consequently intake of HF medications, including BBs.

When comparing the correlation analysis within our two groups, controls and patients, separately, the significant negative association between blood pressure and morning sAA levels persists only in patients, indicating that vasoconstrictor responsiveness to adrenergic stimulation is seriously impaired in HF patients, there is however no significant association between the severity of HF (as indicated by the NYHA class) and any sAA measures. Interestingly, results from our control group did neither come in line with published data that show a positive relationship between sympathetic activity and blood pressure in older men [35]. Our own study group however was considerably older; hence our results could indicate a higher age-related blunting of adrenergic responsiveness of the vascular system than of the salivary glands [36]. 
Other measures of $a$-amylase activity, i.e. the slope of the wakeup response or the daily trajectory, are presumed to be indices of sAA rhythmicity, which, when dysregulated, could possibly indicate increased cardiovascular risk, comparable to an altered circadian blood pressure reflecting higher level of cardiovascular risk in hypertensive or diabetic patients [37]. Our results however do not give an indication that these computed measures of rhythmicity have additional important informative value in HF, when compared to single morning readings.

The fact that we saw a significant positive association between NTproBNP levels and the total output of sAA $\left(\mathrm{AUC}_{\mathrm{G}}\right)$ in the controls, hints at the potential of this non-invasive biomarker for having diagnostic value in early stages of developing HF, which however remains to be investigated. The strong variation between different persons suggest that sAA likely has higher potential as a diagnostic biomarker to be followed in the same individual, i.e. comparing levels in certain time intervals, as it would also be done when monitoring therapeutic treatment effects.

\section{Conclusions}

The small size of the study group together with the large variation of sAA activity levels did not allow us to make definite statements on the value of sAA as a biomarker for HF, however some tendencies emerged which we believe are interesting. Despite the fact that all of our HF patients were undergoing pharmaceutical treatment with BBs, which are known to decrease sAA levels, they tended to have higher sAA levels in the morning than elderly comparatively healthy men of the same age, possibly due to decreased serum medication levels in the morning before drug intake. The observed association of sAA and NTproBNP, a proven diagnostic marker for HF, highlights the possibility of using sAA as a non-invasive biomarker for dysregulations of the neuroendocrine system as in $\mathrm{HF}$, however we predict a higher value for patients not being on BB treatment. Due to the large variability of sAA activity levels, we expect a greater potential for monitoring its changes over time, which could prove a valuable surrogate biomarker for cardiovascular diseases, including HF.

\section{Acknowledgments}

We are grateful to Malin Huss and Anette Gylling who provided excellent help with the set-up of the study and the examination of the participants. This work was financially supported by NovaMedTech and New Tools for Health (HNV).

\section{References}

1. Dickstein K, Cohen-Solal A, Filippatos G, McMurray JJ, Ponikowski P, et al (2008) ESC Guidelines for the diagnosis and treatment of acute and chronic heart failure 2008: the Task Force for the Diagnosis and Treatment of Acute and Chronic Heart Failure 2008 of the European Society of Cardiology. Developed in collaboration with the Heart Failure Association of the ESC (HFA) and endorsed by the European Society of Intensive Care Medicine (ESICM). Eur Heart J 29: 2388-2442.

2. Cohn JN, Levine TB, Olivari MT, Garberg V, Lura D, et al. (1984) Plasma norepinephrine as a guide to prognosis in patients with chronic congestive heart failure. N Engl J Med 311: 819-823.

3. Schrier RW, Abraham WT (1999) Hormones and hemodynamics in heart failure. N Engl J Med 341: 577-585.

4. Iervasi G, Pingitore A (2009) Thyroid and heart failure from pathophysiology to clinics. Springer-Verlag Italia.

5. Clerico A, Recchia FA, Passino C, Emdin M (2006) Cardiac endocrine function is an essential component of the homeostatic regulation network: physiological and clinical implications. Am J Physiol Heart Circ Physiol 290: H17-29.

6. Nater UM, Rohleder N (2009) Salivary alpha-amylase as a non-invasive biomarker for the sympathetic nervous system: Current state of research. Psychoneuroendocrinol 34: 486-496.
7. Granger DA, Kivlighan KT, El-Sheikh M, Gordis EB, Stroud LR (2007) Salivary alpha- amylase in biobehavioral research: recent developments and applications. Ann N Y Acad Sci 1098: 122-144.

8. Rohleder N, Nater UM (2009) Determinants of salivary a-amylase in humans and methodological considerations. Psychoneuroendocrinology 34: 469-485.

9. Proctor GB, Carpenter GH (2007) Regulation of salivary gland function by autonomic nerves. Auton Neurosci 133: 3-18.

10. Bosch JA, Veerman EC, de Geus EJ, Proctor GB (2011) a-Amylase as a reliable and convenient measure of sympathetic activity: don't start salivating just yet! Psychoneuroendocrinology 36: 449-453.

11. Ljungberg G, Ericson T, Ekblom B, Birkhed D (1997) Saliva and marathon running. Scand J Med Sci Sports 7: 214-219.

12. Chatterton RT, Vogelsong KM, Lu YC, Ellman AB, Hudgens GA (1996) Salivary alpha-amylase as a measure of endogenous adrenergic activity. Clin Physiol 16: 433-448.

13. Van Stegerena A, Rohleder N, Everaerd W, Wolf OT (2006) Salivary alpha amylase as marker for adrenergic activity during stress: Effect of betablockade. Psychoneuroendocrinology 31: 137-141.

14. Nederfors T, Dahlof C (1992) Effects of the $\beta$-adrenoceptor antagonists atenolo and propranolol on human whole saliva and composition. Arch Oral Biol 37 579-584.

15. Strahler J, Kirschbaum C, Rohleder N (2011) Association of blood pressure and antihypertensive drugs with diurnal alpha-amylase activity. Int J Psychophysio 81: 31-37.

16. Anand IS, Fisher LD, Chiang Y-T, Latini R, Masson S, et al. (2003) Changes in Brain Natriuretic Peptide and Norepinephrine Over Time and Mortality and Morbidity in the Valsartan Heart Failure Trial (Val-HeFT). Circulation 107: 12781283.

17. Pruessner JC, Kirschbaum C, Meinlschmid G, Hellhammer DH (2003) Two formulas for computation of the area under the curve represent measures of total hormone concentration versus time-dependent change. Psychoneuroendocrinology 28: 916-931.

18. Nater UM, Rohleder N, Schlotz W, Ehlert U, Kirschbaum C (2007) Determinants of the diurnal course of salivary alpha-amylase. Psychoneuroendocrinology 32 392-401.

19. Pfeifer MA, Weinberg CR, Cook D, Best JD, Reenan A, et al. (1983) Differential changes of autonomic nervous system function with age in man. Am J Med 75: 249-258.

20. Veith RC, Featherstone JA, Linares OA, Halter JB (1986) Age differences in plasma norepinephrine kinetics in humans. J Gerontol 41: 319-324.

21. Squires BT (1953) Human salivary amylase secretion in relation to diet. J Physiol 119: 153-156.

22. Al-Tarawneh SK, Border MB, Dibble CF, Bencharit S (2011) Defining Salivary Biomarkers Using Mass Spectrometry- Based Proteomics: A Systematic Review. OMICS 15: 353-361.

23. Haririan H, Bertl K, Laky M, Rausch W-D, Bottcher M, et al. (2012) Salivary and

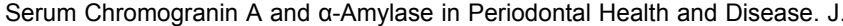
Periodontol.

24. Scannapieco FA, Torres G, Levine MJ (1993) Salivary alpha-amylase: role in dental plaque and caries formation. Crit Rev Oral Biol Med 4: 301-307.

25. Bank RA, Hettema EH, Muijs MA, Pals G, Arwert F, et al. (1992) Variation in gene copy number and polymorphism of the human salivary amylase isoenzyme system in Caucasians. Hum Genet 89: 213-222.

26. Perry GH, Dominy NJ, Claw KG, Lee AS, Fiegler H, et al. (2007) Diet and the evolution of human amylase gene copy number variation. Nat Genet 39 1256-1260.

27. Mandel AL, Peyrot des Gachons C, Plank KL, Alarcon S, Breslin PA (2010) Individual differences in AMY1 gene copy number, salivary a-amylase levels, and the perception of oral starch. PLoS ONE 5: e13352.

28. Hirtz C, Chevalier F, Centeno D, Rofidal V, Egea JC, et al. (2005) MS characterization of multiple forms of alpha-amylase in human saliva. Proteomic 5: 4597-4607.

29. Harmon AG, Towe-Goodman NR, Fortunato CK, Granger DA (2008) 
Citation: Suska A, Alehagen U, Lundstrom I, Dahlstrom U (2012) Salivary Alpha-Amylase Activity, a New Biomarker in Heart Failure? J Clin Exp Cardiolog S2:005. doi:10.4172/2155-9880.S2-005

Differences in saliva collection location and disparities in baseline and diurnal rhythms of alpha-amylase: A preliminary note of caution. Horm Behav 54: 592596.

30. Thomas MV, Branscum A, Miller CS, Ebersole J, Al-Sabbagh M, et al. (2009) Within-subject variability in repeated measures of salivary analytes in healthy adults. J Periodontol 80: 1146-1153

31. DeCaro JA (2008) Methodological considerations in the use of salivary a-amylase as a stress marker in field research. Am J Hum Biol 20: 617-619.

32. de Sa DD, Chen $\mathrm{HH}$ (2008) The role of natriuretic peptides in heart failure. Curr Cardiol Rep 10: 182-189.

33. Abraham WT, Lowes BD, Ferguson DA, Odom J, Kim JK, et al. (1998) Systemic hemodynamic, neurohormonal, and renal effects of a steady-state infusion of human brain natriuretic peptide in patients with hemodynamically decompensated heart failure. J Card Fail 4: 37-44.
34. Brunner-La Rocca HP, Kaye DM, Woods RL, Hastings J, Esler MD (2001) Effects of intravenous brain natriuretic peptide on regional sympathetic activity in patients with chronic heart failure as compared with healthy control subjects. J Am Coll Cardiol 37: 1221-1227.

35. Joyner MJ, Charkoudian N, Wallin BG (2010) Sympathetic nervous system and blood pressure in humans. Individualized patterns of regulation and their implications. Hypertension 56: 10-16.

36. Jones PP, Christou DD, Jordan J, Seals DR (2003) Baroreflex buffering is reduced with age in healthy men. Circulation 107: 1770-1774.

37. Bouhanick B, Chamontin B (2007) Should pulse pressure and day/night variations in blood pressure be seen as independent risk factors requiring correction or simply as markers to be taken into account when evaluating overall vascular risk? Diabetes Metab 33: 321-330.
This article was originally published in a special issue, Cardiac Biomarkers handled by Editor(s). Dr. Virginija Jazbutyte, Institute for Molecular and Translational Therapy Strategies, Germany
Submit your next manuscript and get advantages of OMICS Group submissions

\section{Unique features:}

User friendly/feasible website-translation of your paper to 50 world's leading languages

- Audio Version of published paper

- Digital articles to share and explore

Special features:

200 Open Access Journals

15,000 editorial team

21 days rapid review process

Quality and quick editorial, review and publication processing

Indexing at PubMed (partial), Scopus, DOAJ, EBSCO, Index Copernicus and Google Scholar etc

Sharing Option: Social Networking Enabled

- Authors, Reviewers and Editors rewarded with online Scientific Credits

- Better discount for your subsequent articles

Submit your manuscript at: www.editorialmanager.com/clinicalgroup 